\title{
THE EFFECTS OF JUDICIAL TRANSPARENCY ON PUBLIC TRUST: EVIDENCE FROM A FIELD EXPERIMENT
}

\author{
STEPHAN GRIMMELIKHUIJSEN AND ALBERT KLIJN
}

Trust in judges is needed for voluntary acceptance of judicial decisions, and judicial transparency is thought to strengthen trust. It exposes the public to symbols that embrace a 'myth of legality' which is expected to have a positive effect on trust. We assess a specific understanding of transparency and trust by looking at the moderating effect of knowledge and predisposition to trust. We report on a field experiment which investigates the effect of a Dutch television series on trust. Findings show that judicial transparency indeed has a positive effect on trust. Moreover, our analysis demonstrates that it has the strongest effects on individuals with medium prior knowledge about the judiciary. However, higher predisposition to trust mitigated the effect of transparency, indicating a ceiling effect. This sustains the idea that the unique traits of visual judicial transparency expose typical judicial symbols that imply that impartiality which increases trust in judges.

\section{INTRODUCTION}

The legitimacy of judges is widely thought to be crucial for voluntary acceptance of judicial decisions and maintaining social order (Tyler 2006), and trust is a central component of this. Transparency is seen as an important means of strengthening citizen trust (Gibson and Caldeira 2009; Worthy 2010; Meijer et al. 2012). However, there is intense debate in the academic literature about whether transparency really contributes to trust or whether it even diminishes citizen trust in institutions (Meijer 2009). Indeed, an emerging body of empirical work has offered some evidence that transparency can have negative or at best subdued effects on citizen trust (Worthy 2010; De Fine Licht 2011; Grimmelikhuijsen 2012), which is supposedly due to the exposure of the inherent processes of political decision-making that people dislike, for instance bargaining, brokering, and deal-making in political institutions (Hibbing and Theiss-Morse 1995, 2002; Gibson and Caldeira 2009; Grimmelikhuijsen 2010).

Most work in this area has focused exclusively on the transparency of political institutions and political decision-making, while at the same time researchers have acknowledged the context-dependency of the effects of transparency on trust and legitimacy (Grimmelikhuijsen et al. 2013; Meijer 2013; De Fine Licht 2014). Therefore, we want to further our understanding by investigating the effects of transparency on trust in a crucial and contextually very different institution: the judiciary. The judiciary works differently from political institutions on a critical point, as it is expected to make impartial, independent, and non-political decisions. Transparency exposes people to symbols that embrace this 'myth of legality' (Gibson and Caldeira 2009). These symbols are of particular importance as citizens often lack in-depth knowledge about the judiciary and therefore make symbolic evaluations (Tyler 1998, p. 849; Van de Walle 2009).

Typical symbols such as a gavel, a courtroom, or a gown convey the message that courts are indeed different from other institutions. The message that these symbols put across is that not bargaining or compromise, but impartial and non-political decision-making, take place within courts. For instance, Hibbing and Theiss-Morse (1995) found that more 
awareness of the Congress led to less support, whereas increased awareness of the Supreme Court led to more support for this institution. Based on prior work by Gibson and Caldeira (2009) on media exposure of the Supreme Court, we expect that exposure to these symbols triggers a positivity bias. This bias entails that citizens have certain beliefs about the judiciary that are generally positive. From early in life people are taught that judges are impartial and different. When exposed to typical judicial symbols, these latent positive attitudes of citizens are 'woken up' by the symbols that remind citizens of the impartiality of the judiciary (Gibson et al. 1998; Gibson and Caldeira 2009).

This study seeks to contribute to our understanding of transparency in two ways. First, we conducted a general analysis to assess whether judicial transparency indeed has a positive effect on trust in judges. The second goal of this article is to test a more specific understanding of the effect of transparency. Based on theoretical notions we test how attitudinal changes are affected by pre-existing attitudes and knowledge (Petty and Caccioppi 1986; Bohner 2001; Grimmelikhuijsen and Meijer 2014). Individuals process information differently if they have certain beliefs or attitudes concerning the relevant topic. We hypothesize that citizens with a great deal of knowledge about judges are less receptive to change their trust in this institution. Furthermore, we expect that transparency confirms existing predispositions, that is, positively predisposed citizens become even more trusting; negatively predisposed individuals become less trusting.

The central question we deal with in our article is: To what extent does transparency affect trust in judges and how is this effect related to individual predispositions to trust and knowledge?

In order to assess the question we rely on a field experiment that was carried out in cooperation with a Dutch District Court. The study we report on consisted of a television show about a District Court in the Netherlands that allowed a public television company to cover its daily work. Day-to-day cases were taped and in combination with footage of commentary, deliberations, and personal interviews with judges, were broadcast in eight evening shows. In this sense the series was different from regular mass media coverage mostly focusing on high-profile cases.

\section{TRANSPARENCY AND TRUST IN JUDGES}

Many definitions and operationalizations of trust are used by researchers in the social sciences. However, across disciplines it is generally acknowledged that two conditions are important with regard to trust: (1) a degree of 'risk'; and (2) 'interdependence' (Luhmann 1979; Zucker 1986). Risk and interdependence are crucial because trust is a threefold relationship, in which A trusts B to do X (Hardin 1993). In other words, A expects B to do a certain thing which is in his/her interest. This threefold relation yields a risk as citizens are uncertain as to whether an institution (e.g. the judiciary) actually carries out its tasks the way it is entrusted to. Risk is invoked because government institutions exert a certain degree of power over citizens, which can be used properly or not. Without uncertainty about what an organization does with the trust placed in it there would be no need for trust (Lewis and Weigert 1985). On the other hand, some knowledge is thought to be needed in the process of building trust (Hardin 2002).

Based on these conditions, Rousseau et al. (1998) created a much-used multidisciplinary definition of trust: trust is 'a psychological state comprising the intention to accept vulnerability based upon positive expectations of the intentions or behavior of another' (Rousseau et al. 1998, p. 395). With regard to judges, these expectations are to a large extent connected with the notion of 'procedural fairness'. The centrality of procedural fairness as a driver 
for trust and legitimacy of courts has been recognized in the psychological literature. Psychologists have provided evidence that people base their trust in judges not so much on the outcomes they produce, but on whether they feel individuals are treated fairly (Tyler et al. 1997; Tyler 2001). Thibaut and Walker (1975) originally showed the importance of process-based evaluation in the willingness to accept court decisions. Making the judiciary more transparent contributes to making these processes more visible, and - assuming that (both) parties involved generally receive a fair process - this will increase trust in judges.

The second main concept of this study, transparency, is often related to the extent to which an entity reveals relevant information about its own decision processes, procedures, and performance (Heald 2003; Gerring and Thacker 2004; Welch et al. 2005; Curtin and Meijer 2006; Grimmelikhuijsen 2012). Building on this literature we use the following definition: 'Transparency is the availability of information about an organization or actor allowing external actors to monitor the internal workings or performance' (adapted from Grimmelikhuijsen 2012, p. 55; Grimmelikhuijsen and Welch 2012; Meijer 2013).

Based on this definition, the type of transparency in this study (i.e. informative television series about a Dutch District Court) can be characterized as follows. First, the notion of availability of information in the definition can refer to both proactive and passive transparency (Meijer et al. 2012). Traditionally, judicial transparency has been attained by the openness of cases: in principle everyone is allowed to attend court cases whenever they want. In this study, transparency is taken one step further by bringing it proactively to citizens by broadcasting cases and deliberations on public television. The television series extends the traditional openness in another way; it shows how judges assess a variety of cases in the courtroom and lets them explain decisions afterwards. Although this is a broadening of traditional openness, one can argue that this does not constitute 'complete' transparency and in some respects is a restriction of transparency, because a series is directed and edited. On the other hand, the series was an independent journalistic production and the film makers were given the freedom to tape the cases they wanted. A number of judges were asked if they wanted to participate in the series and, if they consented, their cases could be used in the series. Because the courtroom had a special back wall with a moving camera installed, the consenting judges did not know which of their cases would be used for broadcasting. These are important features that increase transparency.

It is important to note that the visual nature of this type of transparency contributes to the accessibility of the information. Visual information is becoming more important and cultural theorists even argue that we live in a 'visual culture' (e.g. Mirzoeff 1999). The visual nature is in contrast with most transparency initiatives and studies, which tend to focus on textual information, for example on websites or on paper (e.g. Evans and Campos 2013). Visual information, especially in a television series broadcast nationally on public television, is appealing and makes information much easier to comprehend and access than text-based information tucked away on websites.

In sum, this form of judicial transparency can be conceptualized as proactive and visual transparency. The next section will explain how this relates to the expected effects on citizen trust in judges.

\section{POTENTIAL EFFECTS OF JUDICIAL TRANSPARENCY ON TRUST}

The effects of transparency have been heavily debated in the literature (Meijer 2009). Recent empirical work has suggested a subdued and sometimes negative effect of transparency on trust in public institutions (Worthy 2010; De Fine Licht 2011; Grimmelikhuijsen

Public Administration Vol. 93, No. 4, 2015 (995-1011)

(C) 2015 John Wiley \& Sons Ltd. 
2012). However, it seems that the effect of government transparency depends on the type of policy area, as some policies are of a more controversial nature than others (De Fine Licht 2014).

It has been suggested that government institutions suffer from a 'negativity bias'. Negative performance has a much more pronounced effect on citizen attitudes than good performance (Baumeister et al. 2001; James 2011). In this article we argue that judicial transparency is a peculiar case, and different from government transparency because the judiciary is expected to profit from a positivity bias instead.

Research on judicial exposure to media attention suggests that the judiciary has a different position from other democratic institutions (Gibson and Caldeira 2009). Based on an analysis of longitudinal data, they found that citizens respond positively to media exposure about the judiciary. Based on positivity bias theory they explain how media exposure increased perceived legitimacy of the Supreme Court, even when it concerns contentious confirmation hearings. As Gibson et al. (1998, p. 356) explain:

Generally, to be aware of a court is to be supportive of it. This positivity bias may be associated with exposure to the legitimizing symbols that all courts so assiduously promulgate.

Positivity bias occurs because from early in life citizens learn that the judiciary is 'different', that is, they use non-political, impartial forms of decision-making and as such adhere to the 'myth of legality'. If the judiciary is exposed, as transparency does, the symbols that are associated with this distinctness and impartiality are exposed (Gibson and Caldeira 2009 , p. 9). As a result, exposure of the judiciary, even though it might be negative, makes these dormant positive attitudes towards the judiciary salient.

In sum, transparency research has produced mixed results regarding the effect of government transparency, but nevertheless transparency in particular areas is believed to contribute to greater trust (De Fine Licht et al. 2014; Grimmelikhuijsen and Meijer 2014). Judicial transparency is expected to profit from a positivity bias, and therefore positive effects on trust in judges are expected (Gibson and Caldeira 2009). We therefore postulate the following hypothesis:

Hypothesis 1: Judicial transparency is expected to have an overall positive effect on trust in judges.

However, we believe that that the relationship between judicial transparency and trust is more complicated and depends on various psychological factors. To better understand how transparency might affect trust, we need to understand how people process information at the micro-level. This is needed because people process information differently if they already have certain beliefs or knowledge concerning the topic in question. Information will be related and interpreted in terms of their pre-existing knowledge (Bohner 2001). The Elaboration Likelihood Model (ELM), which was developed in the field of social psychology by Petty and Cacioppo (1986), provides a theoretical basis for our analysis.

The ELM study states that attitude change can take place through both effortful and effortless processing of information. The 'central route' of ELM - related to effortful processing of information - proposes that people who are exposed to a persuasive message relate the message to their existing knowledge about the message topic (Bohner 2001, p. 253). Persuasion through the central route is a process that involves deliberative and active information processing in terms of scrutiny.

ELM also proposes a peripheral route based on social identification, conditioning, and the use of heuristics. This route is chosen when people spend limited time or have little knowledge to process a persuasive message. Likewise, people with little knowledge about 
judges can be expected to change their attitude more easily as they cannot relate the new information to existing patterns. Individuals who already have a great deal of knowledge about the judiciary will relate new information to this existing knowledge. As a result, they are expected to have more stable attitudes towards judges and their attitude will be more difficult to change. An application of ELM in the field of public administration has been carried out by Grimmelikhuijsen and Meijer (2014). Following the same logic as proposed here, they found that the attitudes of people with high levels of knowledge were not influenced by government information, whereas citizens who have little knowledge did change their attitude after reading government information.

Based on the above-mentioned theory and findings, we hypothesize that knowledge of the judiciary moderates the relationship between transparency and trust. High levels of prior knowledge are expected to weaken this relation, whereas low levels of knowledge are expected to strengthen it.

Hypothesis 2: High levels of prior knowledge weaken the effect of judicial transparency on trust in judges.

Second, the psychological theory of confirmation bias provides a theoretical basis for the idea that predispositions play a central role in judging information. Confirmation bias is the phenomenon that people use information that is consistent with their beliefs, and that evidence or information that does not fit the beliefs of a person may even be denied. As a result, confirmation bias theory proposes that people tend to search for and use information only if it confirms their own beliefs (Nickerson 1998; Kunda 1999; Baron 2000), which results in overconfidence in these personal beliefs. These are upheld or even strengthened when faced with evidence or information. Confirmation bias also applies to the biased interpretation of information by different individuals. Lord et al. (1979) found that people who have strong prior opinions on an issue tend to accept confirming evidence at face value, whereas disconfirming evidence is subject to more heavy scrutiny and critical evaluation.

People thus seek and use information that confirms their prior beliefs. This might also apply to transparency. The way the same informative television show is interpreted by various people can differ (see Lord et al. 1979). One crucial variable that colours someone's perceptions of information is people's predisposition to trust the judiciary system in general. An individual's propensity affects the likelihood that an individual will trust something or someone. Someone's predisposition to trust is different from specific trust in the sense that it is a rather stable personal trait which differs from person to person and can be seen as the general willingness to trust (Mayer et al. 1995, p. 715; McKnight et al. 2002, p. 336). People with different developmental experiences, personalities, and cultural backgrounds vary in their predisposition to trust. This will influence how much trust one will place in a specific instance.

When we apply this theory to our study, a person's general trust in the judicial system at large can be seen as a relatively stable predisposition, shaped by their personal development experience (see also Gibson and Caldeira 2009). This, in turn, is expected to influence the effect of transparency. For instance, people with a weak predisposition to trust (i.e. they have low levels of trust in the judiciary system) are expected to either disconfirm the information that comes to them through a television show, or will see their negative beliefs endorsed. Instead, those with a strong propensity to trust (i.e. they have high levels of trust in the judiciary system at large already) may feel affirmed in their thoughts that the judiciary is indeed trustworthy. This expectation is supported by Avery (2009), who investigated the moderating role of pre-existing political trust. Those citizens 
with low levels of political trust already do not become more trusting or less trusting, whether they are watching television news or reading newspapers. In contrast, citizens with higher trust levels become more trusting following exposure to newspapers but less trusting following television news exposure. Avery's findings suggest that pre-existing attitudes play an important role in the relation between transparency and trust. Specific research on the judiciary also elucidated the importance of predispositions with regard to judicial legitimacy (Gibson and Caldeira 2009).

Hypothesis 3: High levels of predisposition to trust the judiciary system strengthen the effect of judicial transparency on trust in judges.

\section{METHOD}

\section{Institutional context and design}

The judiciary in the Netherlands is one of the least corrupt in the world; it is listed 14th by Transparency International (2007). Judges in the Netherlands are appointed for life (until their 70th birthday) to strengthen their independent position. They are formally appointed by the head of state (the King), based on the advice of a committee consisting of members of the judiciary, the public prosecutor, and persons who play a societal role. There are no political and open appointment procedures, no 'dissenting opinions', and there is no role for lay judges in the Dutch judicial system.

It might be this closed system of appointments and decision-making that has recently sparked the debate about a more transparent judiciary in the Netherlands. Scientists and other commentators argue that transparency is necessary for high-quality decisions and to restore trust in the judiciary (Prins 2013; Sterk 2013). Public trust in the Dutch judiciary is relatively high at the moment -69 per cent of the population express (a great deal of) trust in judges whereas other public and political institutions consistently receive lower trust scores. However, in recent years (late 1990s and mid-2000s) trust rates dropped at around and sometimes even below 50 per cent (Croes 2011). This is one of the reasons the Utrecht District Court sanctioned the development of a television series on public television by an independent broadcast organization.

The series had an average of 900,000 viewers for each episode, which is a relatively large audience for Dutch television. In comparison, on an average evening without any popular televised events (e.g. an important soccer match) the best-watched show is the evening news on public television, reaching an average daily audience of 1,860,000 (in 2010). Of the treatment group, 40 per cent watched all eight episodes and 66 per cent watched six or more episodes.

To investigate the influence of the series on individual attitudes, this study employed a field experiment and consisted of two groups that both completed a pre-test and a post-test, which is a suitable design for making causal inferences (Shadish et al. 2002).

\section{Manipulation}

The manipulation consisted of an instruction to watch the series. The control group was given no such instruction. More detailed information on the manipulation can be found in the appendix. However, we are not interested in the effect of our instruction as such, but in the effect of the television series that people watched as a result of the instruction. Therefore, we will elaborate on the content of the series in more detail below. 
The television series consisted of eight episodes. In each episode several judges (men and women, young and old) were televised in different types of case. A typical episode had a duration of 25 minutes and covered three very different types of cases. For instance, one episode reported on a night-time stabbing after a night out, a divorce, and an amateur soccer club suing the national soccer association. So, different realms of the judicial practice were presented to the public. These are interesting cases, but far from sensationalist. Each case is presided over by a different judge. However, given the total number of cases, some judges were shown more than once in the full series. An episode contained video material from the case itself, but judges also gave personal testimonies about their earnest deliberations in the particular case. The series was developed relatively free from influence of the court. Judges could self-enrol to participate in the series, but did not know beforehand which cases would be used and broadcast, nor did the court influence how the material was edited.

Although informing the public about the actual work of judges (e.g. providing information and deliberation in a variety of cases) was an important goal of the series, the episodes go beyond merely providing information. The episodes in the series clearly express the symbols and values of the judiciary that undergird the 'myth of legality' (see Gibson and Caldeira 2009). For example, judges are nearly always shown in their robes, the use of the gavel is shown, and the 'rise' of the courtroom is shown repeatedly in each episode. Moreover, the title sequence at the start of each episode shows these symbols repeatedly.

\section{Data collection and sample}

The sample was drawn from an online respondent panel managed by the research company (Mediatest) that regularly carries out public opinion research projects, administering the questionnaires in the pre- and post-test to an online panel. The total panel consists of respondents that are representative for the Dutch population on a number variables, such as age and sex.

A random group from this panel was asked to participate in the project. They were informed about the start of the series and were instructed to watch the episodes as well as filling out surveys that were (and would be) digitally provided by the company. To watch the series we refer to the following website: www.uitzendinggemist.nl/programmas/1890de-rechtbank (accessed 23 May 2014, only in Dutch).

The control group was asked to complete a questionnaire and were told that they would be approached at a later time. Of course, no mention was made of the television show; they were told about the councils' wish to get better informed about trust in the judiciary and the judges as well. Because of the longitudinal design of the research and the required discipline of the participants in watching the show, we expected a high drop-out rate and so we oversampled the treatment group (see table 1).

Altogether, 2,148 people were approached for the treatment group, of whom 1,515 (70.5 per cent) completed the pre-test questionnaire; 585 respondents (27 per cent) completed the post-test questionnaire. A reason for the high percentage of drop-outs may be that respondents who had not watched the show lost interest at an early stage and refrained from completing the post-test questionnaire. In addition, after four episodes (out of eight in total) there was a break of a few weeks in the series because of the Christmas holidays. In this break we sent a reminder to all treatment group respondents to ask them if they 
TABLE 1 Response rates

\begin{tabular}{lllll}
\hline & Approached & Completed pre-test & Completed post-test & Overall response rate \\
\hline Treatment & 2148 & 1516 & 585 & $27.2 \%$ \\
Control & 872 & 811 & 464 & $57.2 \%$ \\
\hline
\end{tabular}

TABLE 2 Sample information for key background variables

\begin{tabular}{llcc}
\hline & Age & $\begin{array}{c}\text { Education } \\
\mathbf{( 1 = h i g h )}\end{array}$ & $\begin{array}{c}\text { Experience } \\
\mathbf{( 1 = \text { prior case) }}\end{array}$ \\
\hline Control $(\mathrm{N}=464)$ & $46.7(13.8)$ & $0.38(0.49)$ & $0.37(0.48)$ \\
Treatment $(\mathrm{N}=585)$ & $42.9(13.5)^{* *}$ & $0.46(0.50)$ & $0.32(0.47)$ \\
\hline
\end{tabular}

${ }^{* * *} \mathrm{p}<0.001 ;{ }^{* *} \mathrm{p}<0.01$.

had watched the series already, and that the series would restart with four remaining episodes in the new year. For the control group 872 people were sampled, of whom 93 per cent responded to the pre-test questionnaire; 464 respondents completed the post-test questionnaire.

The declining response rates in table 1 indicate that there may be some selection bias in the process of sampling. First, there is a relatively high drop-out rate in the treatment group. Presumably, respondents who were reminded to watch the show were more likely to refrain from completing the pre-test questionnaire in the first place. Only 70.5 per cent completed the pre-test questionnaire, whereas 93.0 per cent of the control group did so.

We checked the dataset $(n=1049)$ for comparability on three key background traits: age, education, and prior experience. Tyler (2001) found a positive correlation between age and trust in judges, and Bovens and Wille (2011) asserted that citizens with university degrees tend be more trusting towards government and other public institutions than citizens with lower degrees. Prior experience with courts was taken into account, because prior analyses have shown that this negatively - albeit marginally - affects perceptions of judges (e.g. Van de Walle 2009).

Next we tested for significant differences between groups on these background traits. Ideally, there are no significant differences between the experimental groups because respondents were assigned to experimental groups randomly. Nevertheless, a significant difference was found regarding the average age between the control and treatment groups. Uneven distribution of background traits in experimental groups can be problematic as it may confound the results of the experiment. However, we think that the impact of this bias on the results of this study is limited. First (see table 2), it only has a very weak negative correlation with pre- and post-test trust in judges. Differences between the control and treatment groups are therefore attributable to age to a very limited extent. Furthermore, although the age difference between control and treatment groups is significant, the difference is less than five years, which will make the potential confounding impact of age even smaller. To be certain that this confounding effect is eliminated, we took age into account as a covariate (control variable) in our analyses, to control for its potential confounding effect. 


\section{Measures}

\section{Trust}

In measuring trust, we followed Tyler's operationalization of trust in judges (Tyler 2001). He measured trust in terms of judges are honest, court decisions are fair, courts protect citizen rights, decisions are fair, and the court guarantees everyone a fair trial (Tyler 2001, p. 218). According to Tyler, 'this produces an overall index of confidence or institutional trust'. The items we used were similar to Tyler's; participants were asked to indicate their level of trust on a 5-point scale in the dedication, competence, integrity, impartiality, and decisions of judges (Cronbach's alpha pre-test $=0.91$, Cronbach's alpha post-test $=0.92$ ).

\section{Predisposition to trust}

Predisposition to trust was measured using generalized trust in the criminal justice system as a proxy. This was operationalized using two items: The Dutch justice system is effective in battling crime and The Dutch criminal justice system performs adequately (Cronbach's alpha $=0.748$ ). Both items were assessed on a 5-point scale. Based on these two items, participants could have a mean predisposition score of 1.0, 1.5, 2.0, 2.5, 3.0, 3.5, 4.0, 4.5, or 5.0. To assess the moderation effect of predisposition we devised three subsets of respondents. To determine the borders of the middle category, we used the mean score (2.65) and median score (2.5) on these two items. Therefore, respondents in the 2.5 (median) category and 3.0 (mean) category constituted the moderate predisposition group $(\mathrm{N}=468)$. Participants in the 1.0-2.0 group were assigned to the 'low predisposition' group $(\mathrm{N}=365)$, and the others (3.5-5.0) to the high predisposition group $(\mathrm{N}=216)$.

\section{Knowledge}

Knowledge was measured using an item measuring self-assessed knowledge: How do you assess your knowledge about criminal justice in the Netherlands? The scale ran from 1 (very low) to 5 (very high). To assess the moderator effect of knowledge, we used three subsets of respondents: one set of low knowledgeable respondents (score of 1 or 2), one set of medium knowledgeable respondents (score of 3), and one set of high knowledgeable respondents (score of 4 or 5). This operationalization of knowledge was based on self-assessment and was only measured by one item. In the absence of validated objective measures of judicial knowledge, we considered this the second-best option to serve as a proxy for actual knowledge. To make sure knowledge was not an effect of the treatment, we measured knowledge before the series started; 198 respondents were assigned to the high knowledge subset, 509 to the medium knowledge subset, and 342 to the low knowledge subset.

\section{Analysis}

We used the Instrumental Variables (IV) method to analyse our field experiment. Instrumental variables are useful in cases where there is 'concern that the treatment and unobserved factors that might affect the outcome ... are correlated in some significant way. To be clear, the issue is not assigned treatment, but rather the actual treatment as received and experienced by the subject' (McDermott 2011, p. 31). What would this mean for this study? According to Angrist (2006), the IV method should be applied when treatment compliance is not perfect, as is the case in our field experiment. In other words, several participants who were assigned to the control group still watched the television series.

IV methods can be applied to our study as follows. IV sees the intention to treat as an instrument to the actual explanatory variable, which in our case is the number of 
television shows they watched. This can be tested with a two-stage least squares (2SLS) regression analysis, which first tests the relation between the instrument and explanatory variable, and in the second stage, the effect of the explanatory variable on the dependent variable. We constructed a difference variable of pre-test trust minus post-test trust in judges and entered this as the dependent variable in the equation. We report the betas for the second stage, which designates the effect of television episodes watched on trust in judges: whole population. ${ }^{1}$

\section{RESULTS}

\section{Overall analysis}

We have included a correlation table between key background variables, the two moderating variables (knowledge and predisposition), and the pre-test and post-test trust means in the appendix. The highest correlations occur between predisposition to trust the system and trust in judges. As judges are part of the justice system this makes sense. It should be noted, however, that even though these correlations are high compared to other statistics in the table, they are not anywhere near values that indicate multicollinearity (above 0.8 or 0.9 ). For more details, see the appendix.

First, we analysed the effect of the series on the overall sample. Looking at the regression analysis on the overall population, we found a main effect of the television series on trust in judges $\left(F=22.54, \beta=0.254, p<0.001, R^{2}=0.041\right)$. This indicates a moderate effect of watching the television series: participants who watched more episodes tend to have more trust in judges; 4.1 per cent of the change in trust can be explained by the series. Next, separate analyses were carried out to show how knowledge and predisposition moderates the relationship between judicial transparency and trust. First we will show the results for predisposition, and then for knowledge.

How is the low predisposition group affected by watching the show? The 2SLS regression indeed showed an effect of watching the show $(\beta=0.365, p<0.001)$. This indicates a significant and rather strong effect; transparency explains 9.1 per cent of the variation in trust in judges. The next analysis provides results on how the moderate predisposition group is affected by the series. When we applied 2SLS regression, we again detected a clear effect of the transparency manipulation, although it was less strong $(\beta=0.234, p<0.001)$, explaining 3.5 per cent. Finally the high predisposition group was analysed. The effect remained significant, but was considerably weaker compared to the moderate and low predisposition groups $(\mathrm{F}=4.30, \beta=0.175, \mathrm{p}<0.05)$. Tables $3-5$ display these results. ${ }^{2}$

Second, three separate analyses were carried out to determine the effect of prior knowledge on watching the show. In the low knowledge subset we found an effect of watching the television series $(\beta=0.229, \mathrm{p}<0.01)$, with a reasonable effect size. The size of the effect increased when we carried out the 2SLS regression on the medium knowledge participants $(\beta=0.269, \mathrm{p}<0.001)$. Finally, in the high knowledge group we also found a difference $(\beta=0.225, p<0.01)$, but it was slightly more subdued than in the medium knowledge subset. In conclusion, the television show seems to have a stronger positive effect on people who have some substantial knowledge of the judiciary, compared to participants with (very) little knowledge. Tables 6-8 show the results of analyses of all three subsets.

Overall, a slightly weaker effect can be found in the low knowledge group. A weak effect was found in the high knowledge subset; however, there was a significant difference in pre-test attitudes between the control and treatment groups, which means we should 
TABLE 3 2SLS regression for low predisposition subset $(n=365)$

\begin{tabular}{lll}
\hline & $\begin{array}{l}\text { Step 1: Treatment condition } \rightarrow \\
\text { Number of shows watched }\end{array}$ & $\begin{array}{l}\text { Step 2: Number of shows } \\
\text { watched } \rightarrow \text { Trust in judges }\end{array}$ \\
\hline $\begin{array}{ll}\text { Number of shows watched } \\
\text { Treatment condition }\end{array}$ & $\mathrm{N} / \mathrm{A}$ & $0.365^{* * *}$ \\
Age (control) & $0.832^{* * *}$ & $\mathrm{~N} / \mathrm{A}$ \\
& -0.017 & -0.038 \\
& $\mathrm{~F}=416.85^{* * *}$ & $\mathrm{~F}=19.04^{* * *}$ \\
$\mathrm{R}^{2}=0.697$ & $\mathrm{R}^{2}=0.095$ \\
\hline
\end{tabular}

Assumption of multicollinearity not violated (VIFs do not exceed 1.024). Standardized betas are displayed. ${ }^{*} \mathrm{p}<0.05 ;{ }^{* *} \mathrm{p}<0.01 ;{ }^{* * *} \mathrm{p}<0.001$.

TABLE 4 2SLS regression for moderate predisposition subset $(n=468)$

\begin{tabular}{lll}
\hline & $\begin{array}{l}\text { Step 1: Treatment condition } \\
\text { Number of shows watched }\end{array}$ & $\begin{array}{c}\text { Step 2: Number of shows } \\
\text { watched } \rightarrow \text { Trust in judges }\end{array}$ \\
\hline Number of shows watched & $\mathrm{N} / \mathrm{A}$ & $0.234^{* * *}$ \\
Treatment condition & $0.799^{* * *}$ & $\mathrm{~N} / \mathrm{A}$ \\
Age (control) & -0.052 & 0.044 \\
& $\mathrm{~F}=429.56^{* * *}$ & $\mathrm{~F}=8.37^{* * *}$ \\
& $\mathrm{R}^{2}=0.649$ & $\mathrm{R}^{2}=0.035$ \\
\hline
\end{tabular}

Assumption of multicollinearity not violated (VIFs do not exceed 1.009). Standardized betas are displayed. ${ }^{*} \mathrm{p}<0.05 ;{ }^{* *} \mathrm{p}<0.01 ;{ }^{* * *} \mathrm{p}<0.001$.

TABLE 5 2SLS regression for high predisposition subset $(n=216)$

\begin{tabular}{lll}
\hline & $\begin{array}{l}\text { Step 1: Treatment condition } \\
\text { Number of shows watched }\end{array}$ & $\begin{array}{l}\text { Step 2: Number of shows } \\
\text { watched } \rightarrow \text { Trust in judges }\end{array}$ \\
\hline Number of shows watched & $\mathrm{N} / \mathrm{A}$ & $0.175^{*}$ \\
Treatment condition & $0.791^{* * *}$ & $\mathrm{~N} / \mathrm{A}$ \\
Age (control) & -0.049 & 0.000 \\
& $\mathrm{~F}=187.69^{* * *}$ & $\mathrm{~F}=2.15$ \\
& $\mathrm{R}^{2}=0.638$ & $\mathrm{R}^{2}=0.020$ \\
\hline
\end{tabular}

Assumption of multicollinearity not violated (VIFs do not exceed 1.017). Standardized betas are displayed. ${ }^{*} \mathrm{p}<0.05 ;{ }^{* *} \mathrm{p}<0.01 ;{ }^{* * *} \mathrm{p}<0.001$.

interpret the findings from this subset with some caution; we will return to this in the conclusion and discussion.

To conclude the results section, we carried out an intention to treat (ITT) analysis to test the robustness of our results. ITT is a way to analyse the data in the way intended in the experiment (cf. Angrist et al. 1996). For instance, respondents in the control group who watched the television series anyway are still treated as being in the control group (i.e. the way it was intended by the researcher). This analysis is useful to assess how sensitive our results are for a selection bias that may be caused by the unintended migration of respondents from one experimental group to another. We used ANCOVAs to assess the effect of our intended treatment on the change in trust in judges. The results are presented in table 9. 
TABLE 6 2SLS regression for low knowledge subset $(n=342)$

\begin{tabular}{lll}
\hline & $\begin{array}{l}\text { Step 1: Treatment condition } \\
\text { Number of shows watched }\end{array}$ & $\begin{array}{l}\text { Step 2: Number of shows } \\
\text { watched } \rightarrow \text { Trust in judges }\end{array}$ \\
\hline $\begin{array}{ll}\text { Number of shows watched } \\
\text { Treatment condition }\end{array}$ & $\mathrm{N} / \mathrm{A}$ & $0.229^{* *}$ \\
Age (control) & $0.795^{* * *}$ & $\mathrm{~N} / \mathrm{A}$ \\
& -0.025 & -0.013 \\
& $\mathrm{~F}=294.54^{* * *}$ & $\mathrm{~F}=5.85^{* *}$ \\
& $\mathrm{R}^{2}=0.635$ & $\mathrm{R}^{2}=0.028$ \\
\hline
\end{tabular}

Assumption of multicollinearity not violated (VIFs do not exceed 1.002). Standardized betas are displayed. ${ }^{*} \mathrm{p}<0.05 ;{ }^{* *} \mathrm{p}<0.01 ; * * \mathrm{p}<0.001$.

TABLE 7 2SLS regression for medium knowledge subset $(n=509)$

\begin{tabular}{lll}
\hline & $\begin{array}{l}\text { Step 1: Treatment condition } \\
\text { Number of shows watched }\end{array}$ & $\begin{array}{l}\text { Step 2: Number of shows } \\
\text { watched } \rightarrow \text { Trust in judges }\end{array}$ \\
\hline Number of shows watched & $\mathrm{N} / \mathrm{A}$ & $0.269^{* * *}$ \\
Treatment condition & 0.805 & $\mathrm{~N} / \mathrm{A}$ \\
Age (control) & -0.049 & 0.016 \\
& $\mathrm{~F}=505.95^{* * *}$ & $\mathrm{~F}=12.23^{* * *}$ \\
& $\mathrm{R}^{2}=0.667$ & $\mathrm{R}^{2}=0.046$ \\
\hline
\end{tabular}

Assumption of multicollinearity not violated (VIFs do not exceed 1.043). Standardized betas are displayed. ${ }^{*} \mathrm{p}<0.05 ;{ }^{* *} \mathrm{p}<0.01 ;{ }^{* * *} \mathrm{p}<0.001$.

TABLE 8 2SLS regression for high knowledge subset $(n=198)$

\begin{tabular}{|c|c|c|}
\hline & $\begin{array}{l}\text { Step 1: Treatment condition } \rightarrow \\
\text { Number of shows watched }\end{array}$ & $\begin{array}{l}\text { Step 2: Number of shows } \\
\text { watched } \rightarrow \text { Trust in judges }\end{array}$ \\
\hline Number of shows watched & $\mathrm{N} / \mathrm{A}$ & $0.225^{* *}$ \\
\hline Treatment condition & $0.834^{* * *}$ & N/A \\
\hline \multirow{3}{*}{ Age (control) } & -0.043 & 0.132 \\
\hline & $\mathrm{F}=236.09^{* * *}$ & $\mathrm{~F}=4.56^{*}$ \\
\hline & $R^{2}=0.708$ & $\mathrm{R}^{2}=0.045$ \\
\hline
\end{tabular}

Assumption of multicollinearity not violated (VIFs do not exceed 1.021). Standardized betas are displayed. ${ }^{*} \mathrm{p}<0.05 ;{ }^{* *} \mathrm{p}<0.01 ;{ }^{* * *} \mathrm{p}<0.001$.

These results in table 9 are very similar to those reported in the 2SLS regression. Again the results show the mitigating effect of one's predisposition to trust the judicial system. With regard to self-assessed knowledge, the ITT analysis shows something new. While the treatment group mean increased almost as much as in the medium knowledge subset, the overall difference is smaller because of an increase in trust in the control group. The overall conclusion from the 2SLS regressions - that the treatment has the strongest effect for those with a medium level of knowledge - is nevertheless upheld by this auxiliary analysis.

\section{CONCLUSION AND DISCUSSION}

The results of our study indicate that there is an overall positive effect of judiciary transparency on trust in judges. Hypothesis 1 is therefore supported. Our positive result 
TABLE 9 ITT analyses using ANCOVAs

\begin{tabular}{|c|c|c|c|}
\hline & $\begin{array}{l}\text { Mean change in trust } \\
\text { in control group }\end{array}$ & $\begin{array}{l}\text { Mean change in trust } \\
\text { in treatment group }\end{array}$ & \\
\hline General analysis & 0.078 & $0.322^{* * *}$ & $\begin{array}{l}\mathrm{F}=45.20^{* * *} \\
\text { Partial } \eta^{2}=0.041\end{array}$ \\
\hline Low PD & 0.120 & $0.519^{* * *}$ & $\begin{array}{l}F=36.19^{* * *} \\
\text { Partial } \eta^{2}=0.091\end{array}$ \\
\hline Moderate PD & 0.101 & $0.307^{* * *}$ & $\begin{array}{l}F=16.74^{* * *} \\
\text { Partial } \eta^{2}=0.035\end{array}$ \\
\hline High PD & -0.074 & $0.092^{*}$ & $\begin{array}{l}F=4.095^{*} \\
\text { Partial } \eta^{2}=0.019\end{array}$ \\
\hline Low knowledge & 0.055 & $0.262^{* *}$ & $\begin{array}{l}\mathrm{F}=11.65^{* * *} \\
\text { Partial } \eta^{2}=0.033\end{array}$ \\
\hline Medium knowledge & 0.081 & $0.350^{* * *}$ & $\begin{array}{l}\mathrm{F}=23.86^{* * *} \\
\text { Partial } \eta^{2}=0.045\end{array}$ \\
\hline High knowledge & 0.127 & $0.341^{* *}$ & $\begin{array}{l}F=7.04^{* *} \\
\text { Partial } \eta^{2}=0.035\end{array}$ \\
\hline
\end{tabular}

The table shows the mean change between the pre-test and post-test on a 5-point scale. *Differs at $p<0.05$. ** Differs at $\mathrm{p}<0.01 .{ }^{* * *}$ Differs at $\mathrm{p}<0.001$. All analyses include 'Age' as a covariate.

is in contrast with recent studies that found a negative effect of transparency of government and political institutions on citizen trust (Worthy 2010; De Fine Licht 2011; Grimmelikhuijsen 2012). On the other hand, the positive result does resonate with the study of Gibson and Caldeira (2009) who found that the judiciary is 'different' from other institutions in the sense that it profits from a positivity bias, which is a result of exposure to symbols that capture the 'myth of legality': the judiciary is impartial and has non-political mechanisms of decision-making. In the debate on transparency this is a significant finding as researchers have only begun to discover the influence of various contextual variables on the relationship between transparency, trust, and legitimacy (e.g. Grimmelikhuijsen et al. 2013; De Fine Licht 2014).

Our study adds two important elements to this general finding, namely the influence of prior knowledge and predisposition to trust the criminal justice system. The second hypothesis predicted a mitigating influence of knowledge on the relation between transparency and trust. This was partly supported by our results. The least pronounced effect was found for the high knowledge group. However, this finding should be interpreted with caution because we found rather large differences in the pre-test trust score of participants. ${ }^{3}$ We further found that the effect of transparency was strongest for people with medium knowledge, which indicates that transparency works best for those citizens who have some basic knowledge about the judiciary. This makes sense as basic knowledge about the judiciary is needed to place the information the series has to offer in a proper frame of reference.

Overall, the ELM model for processing information (Petty and Cacioppo 1986) seems to work quite well in predicting the moderating effect of knowledge. Based on this model we predicted that citizens who do not know that much about the judiciary will more easily add new information to their current patterns of thinking, which will lead to a faster attitude change compared to citizens with high levels of knowledge. This was especially true for those who had moderate knowledge of the judiciary. 
This is a relevant finding for practitioners, too. The fact that the type of transparency under study is most effective on medium knowledgeable citizens seems to be promising. Classic, text-based, types of transparency often reach a limited audience, presumably high knowledge and well-educated citizens. However, in this case of visual transparency a different and broader audience is reached, and specifically an audience that is more likely to gain trust by this type of transparency: approximately 75 per cent of our sample report having 'little' to 'medium' knowledge. This means that transparency can be valuable to reach out to a broader public that is otherwise less knowledgeable about public institutions.

Hypothesis 3 is rejected based on our findings. Individuals with a high predisposition to trust showed less increase between reported trust in judges before and after, disconfirming hypothesis 3. Based on the theory of confirmation bias (e.g. Nickerson 1998) we predicted that people with a positive predisposition towards the justice system were more likely to increase their trust. Since our results proved otherwise, we need an alternative explanation for our finding that citizens with high predispositions were less likely to increase their trust. A simple alternative explanation is the existence of a ceiling effect to trust. Individuals with a high predisposition concerning the justice system will not easily gain even more trust by watching a television show. Citizens with relatively little trust have much more 'room' to increase their trust in judges.

A limitation is our focus on the immediate influence of a one-off series and we did not investigate what specific cues were most beneficial for trust in judges. These limitations provoke some new questions that should be tackled in future research. For instance, to what extent will the positive effect of watching the series last? To what extent can the positive effect of watching the series counter negative experiences with courts, for instance negative reports by the press? Furthermore, we investigated the influence of the series as a whole. More rigorous - laboratory - experiments would be needed to assert this. That said, a field setting more closely aligns with a real life setting in which people watch a series at home on their couch, and not in a laboratory. A final question for future research would be to assess cultural differences. In other countries where people hold less favourable views regarding the judiciary, for instance because of a deeply corrupt judicial system, positivity bias might not apply. More work is needed to further our understanding of these contextual influences on trust and judicial transparency.

That said, the main conclusion of this study is fairly optimistic and shows that transparency in the judicial context can contribute to trust. This can be explained by the unique traits of visual judicial transparency: the exposure to typical judicial symbols that imply impartiality and non-political decision-making triggers a positivity bias among citizens. Transparency seems to be fit to trigger these positive symbolic evaluations in order to win the hearts and minds of the public.

\section{ACKNOWLEDGEMENTS}

The authors would like to thank Paul Boselie, Albert Meijer and Ulrike Weske for their feedback on an earlier version of this article. Also they are thankful for Marnix Croes' help in designing the experiment. They are also grateful to the anonymous reviewers for their valuable comments.

\section{NOTES}

${ }^{1}$ For further details on IV methods in social science, see Angrist (2006). 
${ }^{2}$ We carried out an additional regression analysis in which the predisposition variable was included as an interaction term in a 'regular' OLS regression analysis. In this additional regression (DV = difference between pre- and post-test) analysis we found similar results: a negative effect of the moderating variable predisposition $(\beta=-0.174, p<0.001)$.

${ }^{3}$ In the high knowledge subset we found large pre-test differences for trust ( 2.83 in the control group and 3.22 in the treatment group; $(\mathrm{F}(1,196)=9.20, \mathrm{p}=0.003)$ and increase in trust in both the control and the experimental group. This indicates that there is some self-selection bias present. Critical and knowledgeable respondents were less likely to decide to watch the show as compared to trusting and knowledgeable respondents. The second issue - an increase in trust in both the treatment and control groups - suggests that exogenous factors have a relatively large influence on respondents with high knowledge compared to other respondents. Highly knowledgeable citizens may follow the news about the judiciary much more closely by means of other sources, resulting in a marginal influence of the television series.

\section{REFERENCES}

Angrist, J.D. 2006. 'Instrumental Variables Methods in Experimental Criminological Research: What, Why and How', Journal of Experimental Criminology, 2, 1, 23-44.

Angrist, J.D., G.W. Imbens and D.B. Rubin. 1996. 'Identification of Causal Effects Using Instrumental Variables', Journal of the American Statistical Association, 91, 434, 444-55.

Avery, J.M. 2009. 'Videomalaise or Virtuous Circle? The Influence of the News Media on Political Trust', International Journal of Press/Politics, 14, 4, 410-33.

Baron, J. 2000. Thinking and Deciding, 3rd edn. New York: Cambridge University Press.

Baumeister, R.F., E. Bratslavsky, C. Finkenauer and K.D. Vohs. 2001. 'Bad is Stronger than Good', Review of General Psychology, 5 , $4,323-70$

Bohner, G. 2001. 'Attitudes', in M. Hewstone and W. Stroebe (eds), Introduction to Social Psychology. Malden: Blackwell Publishing, pp. 239-82.

Bovens, M. and A. Wille. 2011. Diplomademocratie: Over de spanning tussen meritocratie en democratie [Diploma Democracy: About the Tension between Meritocracy and Democracy]. Amsterdam: Prometheus.

Croes, M.T. 2011. 'Heeft de burger vertrouwen in de rechter? [Do Citizens Trust Judges?]', in M. Hertogh and H. Weyers (eds), Recht van onderop. Antwoorden uit de rechtssociologie. Nijmegen: Ars Aequi Libri, pp. 301-24.

Curtin, D. and A.J. Meijer. 2006. 'Does Transparency Strengthen Legitimacy?', Information Polity, 11, 2, 109-23.

De Fine Licht, J. 2011. ‘Do We Really Want to Know? The Potentially Negative Effect of Transparency in Decision Making on Perceived Legitimacy', Scandinavian Political Studies, 34, 3, 183-201.

De Fine Licht, J. 2014. 'Policy Area as a Potential Moderator of Transparency Effects: An Experiment', Public Administration Review, $74,3,361-71$.

De Fine Licht, J., D. Naurin, P. Esaiasson and M. Gilljam. 2014. 'When Does Transparency Generate Legitimacy? Experimenting on a Context-Bound Relationship', Governance, 27, 1, 111-34.

Evans, A.M. and A. Campos. 2013. 'Open Government Initiatives: Challenges of Citizen Participation', Journal of Policy Analysis and Management, 32, 1, 172-203.

Gerring, J. and S.C. Thacker. 2004. 'Political Institutions and Corruption: The Role of Unitarism and Parliamentarism', British Journal of Political Science, 34, 2, 295-330.

Gibson, J.L. and G.A. Caldeira. 2009. Citizens, Courts, and Confirmations: Positivity Theory and the Judgments of the American People. Princeton, NJ: Princeton University Press.

Gibson, J.L., G.A. Caldeira and V.A. Baird. 1998. 'On the Legitimacy of National High Courts', American Political Science Review, $92,2,343-58$.

Grimmelikhuijsen, S.G. 2010. 'Transparency of Public Decision-Making: Towards Trust in Local Government?', Policy and Internet, 2,1 , article 1 .

Grimmelikhuijsen, S.G. 2012. 'Transparency and Trust: An Experimental Study of Online Disclosure and Trust in Government'. Dissertation, Utrecht University.

Grimmelikhuijsen, S.G. and A.J. Meijer. 2014. 'The Effects of Transparency on the Perceived Trustworthiness of a Government Organization: Evidence from an Online Experiment', Journal of Public Administration Research and Theory, 24, 1, $137-57$.

Grimmelikhuijsen, S.G. and E.W. Welch. 2012. 'Developing and Testing a Theoretical Framework for Computer-Mediated Transparency of Local Governments', Public Administration Review, 72, 4, 562-71.

Grimmelikhuijsen, S.G., G. Porumbescu, B. Hong and T. Im. 2013. 'The Effect of Transparency on Trust in Government: A Cross-National Experiment', Public Administration Review, 73, 4, 575-86.

Hardin, R. 1993. 'The Street-Level Epistemology of Trust', Politics and Society, 21, 4, 505-29.

Hardin, R. 2002. Trust and Trustworthiness, Russell Sage Foundation Series on Trust. New York: Russell Sage Foundation.

Heald, D. 2003. 'Fiscal Transparency: Concepts, Measurement and UK Practice', Public Administration, 81, 4, 723-59.

Hibbing, J.R. and E. Theiss-Moore. 1995. Congress as Public Enemy: Public Attitudes toward American Political Institutions. Cambridge: Cambridge University Press. 
Hibbing, J.R. and E. Theiss-Moore. 2002. Stealth Democracy: Americans' Beliefs about How Government Should Work. Cambridge: Cambridge University Press.

James, O. 2011. 'Managing Citizens' Expectations of Public Service Performance: Evidence from Observation and Experimentation in Local Government', Public Administration, 89, 4, 1419-35.

Kunda, Z. 1999. Social Cognition: Making Sense of People. Cambridge, MA: MIT Press.

Lewis, J.D. and A. Weigert. 1985. 'Trust as a Social Reality', Social Forces, 63, 4, 967-85.

Lord, C.G., L. Ross and M.R. Lepper. 1979. 'Biased Assimilation and Attitude Polarization: The Effects of Prior Theories on Subsequently Considered Evidence', Journal of Personality and Social Psychology, 37, 11, 2098-109.

Luhmann, N. 1979. Trust and Power. Chichester: Wiley.

Mayer, R., J.H. Davis and D. Schoorman. 1995. 'An Integrative Model of Organizational Trust', Academy of Management Review, 20, 3, 709-34.

McDermott, R. 2011. 'Internal and External Validity', in J.N. Druckman, P.G. Green, J.H. Kuklinski and A. Lupia (eds), Cambridge Handbook of Experimental Political Science. Cambridge: Cambridge University Press, pp. 27-40.

McKnight, D.H., V. Choudhury and C. Kacmar. 2002. 'Developing and Validating Trust Measures for E-Commerce: An Integrative Typology', Information Systems Research, 13, 3, 334-59.

Meijer, A.J. 2009. 'Understanding Computer-Mediated Transparency', International Review of Administrative Sciences, 75, 2, $255-69$.

Meijer, A.J. 2013. 'Understanding the Complex Dynamics of Transparency', Public Administration Review, 73, 3, 429-39.

Meijer, A.J., D. Curtin and M.Z. Hillebrandt. 2012. ‘Open Government: Connecting Vision and Voice', International Review of Administrative Sciences, 78, 1, 10-29.

Mirzoeff, N. 1999. An Introduction to Visual Culture. New York: Routledge.

Nickerson, R.S. 1998. 'Confirmation Bias: An Ubiquitous Phenomenon in Many Guises', Review of General Psychology, 2, 2, 175-220.

Petty, R.E. and J.T. Cacioppo. 1986. Communication and Persuasion: Central and Peripheral Routes to Attitude Change. New York: Springer-Verlag.

Prins, C. 2013. 'Rechtspraak en transparantie: inbreng voor een noodzakelijk debat [The Judiciary and Transparency: Input for a Necessary Debate]', Rechtstreeks, 9, 16-37.

Rousseau, D., S. Sitkin, R. Burt and C. Camerer. 1998. 'Not So Different After All: A Cross-Discipline View of Trust', Academy of Management Review, 23, 3, 393-404.

Shadish, W.R., T.D. Cook and D.T. Campbell. 2002. Experimental and Quasi-Experimental Designs for Generalized Causal Inference. Boston/New York: Houghton Mifflin Company.

Sterk, K. 2013. 'Naar een meer open karakter van de rechtspraak [Towards a More Open Character of the Judiciary]', Rechtstreeks, 9, 12-15.

Thibaut, J. and L. Walker. 1975. Procedural Justice. Hillsdale, NJ: Erlbaum.

Transparency International. 2007. Global Corruption Report 2007. Cambridge: Cambridge University Press.

Tyler, T.R. 1998. 'Public Mistrust of the Law: A Political Perspective', University of Cincinnati Law Review, 66, 847-76.

Tyler, T.R. 2001. 'Public Trust and Confidence in Legal Authorities: What do Majority and Minority Group Members Want from the Legal and Legal Institutions?', Behavioral Sciences and the Law, 19, 2, 215-35.

Tyler, T.R. 2006. Why People Obey The Law. Princeton, NJ: Princeton University Press.

Tyler, T.R., R. Boeckmann, J.J. Smith and Y.J. Huo. 1997. Social Justice in a Diverse Society. Denver, CO: Westview.

Van de Walle, S. 2009. 'Confidence in the Criminal Justice System: Does Experience Count?', British Journal of Criminology, 49, 3, 384-98.

Welch, E.W., C.C. Hinnant and M.J. Moon. 2005. 'Linking Citizen Satisfaction with E-Government and Trust in Government', Journal of Public Administration Research and Theory, 15, 3, 371-91.

Worthy, B. 2010. 'More Open but Not More Trusted? The Effect of the Freedom of Information Act 2000 on the United Kingdom Central Government', Governance, 23, 4, 561-82.

Zucker, L.G. 1986. 'Production of Trust: Institutional Sources of Economics Structures, 1840-1920', in B.M. Staw and L.L. Cummings (eds), Research in Organizational Behavior. Greenwich, CT: JAI Press, pp. 53-122.

\section{APPENDIX: INVITATIONS TEXT AND INSTRUCTIONS FOR PARTICIPANTS (ENGLISH TRANSLATIONS)}

\section{Control group: pre-test invitation}

Judicial decisions are an important topic of conversation these days. Many citizens have an opinion about the behaviour of judges, ranging from agreement to criticism. The Dutch judiciary want to stay up-to-date on the opinion of citizens about the judiciary and judges. 
That is why this research is being carried out. What are your experiences and what is your perception of judges?

By participating in this study you contribute to knowledge in the Dutch judiciary about how society perceives judges. This way the judiciary will be even better able to serve citizens.

This study consists of the following parts: we ask your opinion at this moment, then your opinion after two months.

\section{Treatment group: pre-test invitation}

Judicial decisions are an important topic of conversation these days. Many citizens have an opinion about the behaviour of judges, ranging from agreement to criticism. The Dutch judiciary want to stay up-to-date on the opinion of citizens about the judiciary and judges. That is why this research is being carried out. What are your experiences and what is your perception of judges?

We kindly ask you to participate in this study. Soon a new series about the judiciary will begin on television. This series is an important part of this research. To participate in this study the following applies:

1. You have to watch a number of episodes of the series.

2. This study consists of the following parts: we ask your opinion at this moment, then your opinion after two months.

3. The first episodes air on 30 November and then on 7, 14, and 21 December. In January a few more episodes will follow.

4. The series is broadcast on Tuesday nights at $10.30 \mathrm{pm}$ on Channel 1 .

5. You can watch each episode directly, record it or watch it on the internet.

Click 'Start' to begin the questionnaire.

\section{Correlation matrix of key variables}

\begin{tabular}{|c|c|c|c|c|c|c|c|}
\hline & 1 & 2 & 3 & 4 & 5 & 6 & 7 \\
\hline 1. Age & $44.6(13.9)$ & & & & & & \\
\hline 2. Gender ( $2=$ female $)$ & -0.012 & $1.46(0.50)$ & & & & & \\
\hline 3. Education* ${ }^{*}(1=$ high $)$ & $-0.220^{* *}$ & $-0.083^{* *}$ & $0.42(0.49)$ & & & & \\
\hline 4. Knowledge $(1-5)$ & 0.037 & $-0.170^{* *}$ & $-0.134^{* *}$ & $2.81(0.86)$ & & & \\
\hline 5. Predisposition $(1-5)$ & $-0.136^{* *}$ & -0.044 & $0.124^{* *}$ & -0.031 & $2.64(0.80)$ & & \\
\hline $\begin{array}{l}\text { 6. Pre-test trust in } \\
\text { judges }(1-5)\end{array}$ & $-0.136^{* *}$ & 0.003 & $0.165^{* *}$ & -0.053 & $0.545^{* *}$ & $3.14(0.75)$ & \\
\hline $\begin{array}{l}\text { 7. Post-test trust in } \\
\text { judges }(1-5)\end{array}$ & $-0.152^{* *}$ & 0.029 & $0.160^{* *}$ & 0.024 & $0.447^{* *}$ & $0.664^{* *}$ & $3.36(0.71)$ \\
\hline
\end{tabular}

**Correlation is significant at the 0.01 level (2-tailed).

*Correlation is significant at the 0.05 level (2-tailed).

Means (SD) are displayed in italics. Pearson correlation coefficients are displayed, Spearman correlation coefficients are displayed for correlations that involve 'knowledge'.

Education: high $=$ higher vocational and university degree.

$\mathrm{n}=1,049$. 